\title{
Produtividade de milho solteiro ou em aléias de gliricídia adubado com duas fontes orgânicas
}

\author{
Aldrin Martin Pérez Marin ${ }^{(1)}$, Rômulo Simões Cezar Menezes ${ }^{(2)}$ e Ignácio Hernán Salcedo ${ }^{(2)}$
}

\begin{abstract}
(1)Empresa Pernambucana de Pesquisa Agropecuária, Solos e Nutrição de Plantas, Av. das Nações, s/no, CEP 56300-000 Petrolina, PE. E-mail: aldrin@ipa.br (2)Universidade Federal de Pernambuco, Dep. de Energia Nuclear, Av. Prof. Luiz Freire, no 1.000, CEP 50740-540 Recife, PE. E-mail: rmenezes@ufpe.br, salcedo@ufpe.br
\end{abstract}

\begin{abstract}
Resumo - O objetivo deste trabalho foi avaliar a produtividade de biomassa de milho, solteiro ou consorciado com gliricídia (Gliricidia sepium), e o efeito da adubação, com esterco e ramas de gliricídia, sobre a produtividade de milho e da vegetação espontânea. O trabalho foi conduzido de 2003 a 2005, em uma área com fileiras de gliricídia, espaçadas $6 \mathrm{~m}$ entre si e $1 \mathrm{~m}$ entre as árvores, em um Neossolo Regolítico, em Esperança, PB. $\mathrm{O}$ delineamento experimental foi o de blocos ao acaso e parcelas subdivididas, com dois tratamentos principais (presença e ausência de aléias de gliricídia), três tratamentos secundários (testemunha, adubação com esterco, adubação com ramas de gliricídia), e quatro repetições. Nos $1^{\circ}$, $2^{\circ}$ e $3^{\circ}$ anos do estudo, a produtividade de grãos de milho, no sistema sem gliricídia, foi 268,129 e $116 \%$ maior que em presença de árvores, respectivamente. Entretanto, a produtividade total de biomassa (soma da biomassa produzida pelo milho, gliricídia e vegetação espontânea) foi 86,120 e $37 \%$ maior no sistema com árvores nos $1^{\circ}, 2^{\circ}$ e $3^{\circ}$ anos, respectivamente. A produtividade de milho e de vegetação espontânea não diferiu entre as parcelas adubadas com esterco ou gliricídia, mas essas duas fontes orgânicas aumentaram significativamente a produtividade, comparadas à testemunha.
\end{abstract}

Termos para indexação: Agreste, sistemas agroflorestais, adubo-verde.

\section{Productivity of maize intercropped or not with gliricidia ammended with two organic fertilizers}

\begin{abstract}
The objective of this work was to evaluate biomass productivity of maize, intercropped or not with gliricidia (Gliricidia sepium), and to evaluate the effect of manure and gliricidia prunnings fertilization on maize and spontaneous vegetation biomass productivity. The work was conducted from 2003 to 2005 within an area with gliricidia rows, spaced $6 \mathrm{~m}$ between each other and $1 \mathrm{~m}$ between trees, in a Typic Usthorthent, in Esperança, $\mathrm{PB}$, Brazil. The experimental design was a randomized split plot with two main treatments (with and without gliricidia), and three secondary treatments (control, fertilization with manure, fertilization with gliricidia prunnings), with four replications. During the $1^{\text {st }}, 2^{\text {nd }}$ and $3^{\text {rd }}$ years of the study, maize grain productivity in the plots without gliricidia were 268, 129 and $116 \%$ greater than yield of plots with trees, respectively. However, total biomass productivity (sum of the biomass produced by maize, gliricidia and spontaneous vegetation) was 86,120 and $37 \%$ greater in the plots with gliricidia in the $1^{\text {st }}, 2^{\text {nd }}$ and $3^{\text {rd }}$ years of the study, respectively. Maize and spontaneous vegetation biomass productivity did not differ between plots fertilized with manure or gliricidia prunnings, but these two organic fertilizers led to significantly greater biomass productivity compared to the control plots.
\end{abstract}

Index terms: Agreste, agroforestry systems, green manure.

\section{Introdução}

Os solos da Região do Semi-Árido nordestino são deficientes em nutrientes, principalmente $\mathrm{NeP}$ (Sampaio et al., 1995). O uso de fertilizantes químicos é muito reduzido, em razão do custo e do risco causado pela variabilidade do regime de chuvas (Sampaio et al., 1995). Assim, o manejo da fertilidade do solo depende, principalmente, do manejo da matéria orgânica (Tiessen et al., 1992). O esterco é uma fonte de nutrientes, utilizada ampla- mente na região, porém não é disponível em quantidade suficiente nas propriedades rurais, para suprir a demanda das culturas agrícolas. Como alternativa, a prática da adubação verde com gliricídia vem sendo adotada nos últimos anos.

A gliricídia (Gliricidia sepium) é uma leguminosa arbórea, resistente à seca, que vem sendo cultivada como fonte de forragem e lenha em propriedades rurais no Semi-Árido nordestino. Em razão de sua alta capacidade de fixar nitrogênio atmosférico (Bala et al., 2003) e de 
produzir biomassa, em condições de baixa disponibilidade hídrica, a gliricídia é uma planta capaz de melhorar a fertilidade do solo e de aumentar a produtividade das culturas agrícolas associadas, quando usada como aduboverde (Barreto \& Fernandes, 2001), por isso, essa espécie é ideal para o cultivo em aléias (Palm et al., 2001; Vanlauwe et al., 2005).

Sistemas agroflorestais, como o cultivo em aléias ou a implantação de cercas-vivas com gliricídia, vêm sendo adotados em propriedades agrícolas familiares no Agreste paraibano. O sistema em aléias consiste no plantio de árvores ou arbustos, geralmente leguminosas, em fileiras suficientemente espaçadas para permitir o plantio de culturas agrícolas entre elas (Sanchez, 1995). O manejo desse sistema é baseado em cortes periódicos da parte aérea das espécies arbóreas, geralmente entre dois a três cortes por ano, e na utilização da biomassa na alimentação animal ou para incorporação ao solo como adubo-verde.

As espécies arbóreas requerem os mesmos recursos que as culturas associadas, o que pode resultar tanto em interações positivas (complementariedade) quanto negativas (competição). Entre as interações competitivas da associação árvore-cultivo destacamse a competição por luz, água e nutrientes, além de possíveis relações alelopáticas (Schroth et al., 1995). Entre as interações de complementariedade destacamse o suprimento de nutrientes dentro da zona radicular das culturas através da entrada de $\mathrm{N}_{2}$ por fixação biológica, a redução das perdas de nutrientes por lixiviação devido à sua absorção de camadas mais profundas, e a reciclagem de resíduos orgânicos provenientes da deposição de serapilheira ou, ainda, da incorporação de biomassa por meio da adubação-verde (Buresh \& Tian, 1998; Rowe \& Cadisch, 2002; Bala et al., 2003). A magnitude e o tipo de interação, que ocorrem entre as árvores e os cultivos, dependem das condições edafoclimáticas de cada local, das características das plantas utilizadas, do manejo e da eficiência do uso da água, além de outros fatores (Goméz et al., 1990; Rowe et al., 2001; Gathumbi et al., 2003).

No Agreste, não existem informações sobre a complementariedade ou competição de espécies arbóreas, como a gliricídia e culturas associadas, em sistemas de cultivo em aléias, para a agricultura familiar.

O objetivo deste trabalho foi avaliar a produtividade de biomassa de milho, com ou sem a presença de gliricídia, e o efeito da adubação com esterco ou com ramas de gliricídia, sobre a produtividade do milho e da vegetação espontânea.

\section{Material e Métodos}

O trabalho foi desenvolvido nos anos de 2003, 2004 e 2005, no Centro Agroecológico São Miguel (CASM), sede da ONG Assessoria e Serviços a Projetos de Agricultura Alternativa (AS-PTA), no Município de Esperança, no Agreste paraibano ( $7^{\circ} 19^{\prime} \mathrm{S}$ e $33^{\circ} 51^{\prime} \mathrm{W}, 635 \mathrm{~m}$ de altitude). A região apresenta estação chuvosa de março a agosto, e estação seca de setembro a fevereiro. A precipitação pluvial média anual é de 800 mm, e os totais anuais em 2003, 2004 e 2005 foram 648, 1.000 e $668 \mathrm{~mm}$, respectivamente (Figura 1). O solo na área experimental é classificado como Neossolo Regolítico, textura franco-arenosa e com declividade em torno de $5 \%$. As fileiras de gliricídia foram plantadas em 1996, em área de aproximadamente 0,5 ha, com um espaçamento de $6 \mathrm{~m}$ entre fileiras e $1 \mathrm{~m}$ entre as plantas.

O delineamento experimental utilizado foi o de blocos ao acaso, em parcelas subdivididas, com quatro repetições. Em 2003, dentro da área experimental, foram demarcadas quatro parcelas de $144 \mathrm{~m}^{2}$ cada $(6 \times 24 \mathrm{~m})$, que corresponderam ao tratamento principal com aléias de gliricídia consorciadas com milho (com aléia-CA). Adjacentes a essas, em áreas sem gliricídia, foram estabelecidas parcelas de mesmo tamanho, nas quais

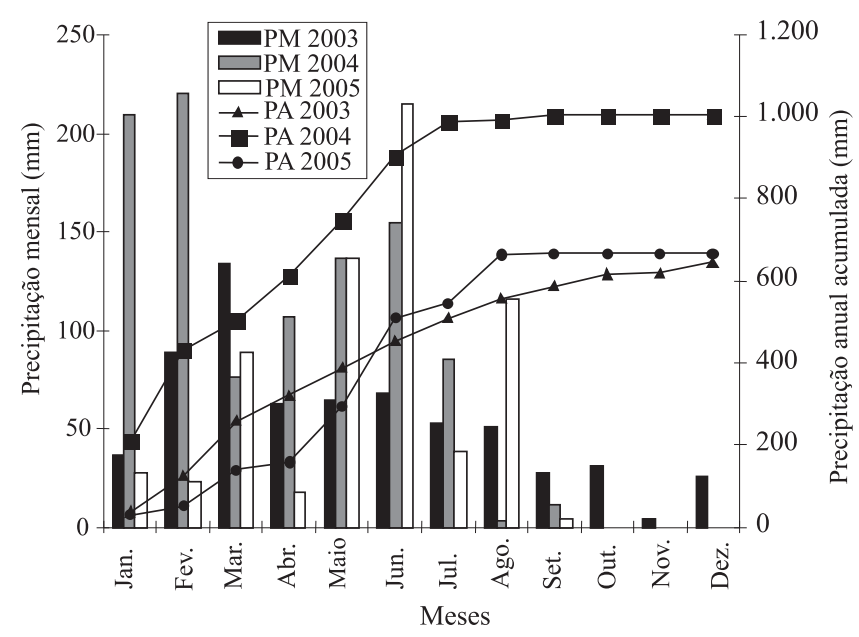

Figura 1. Precipitação pluvial mensal (PM) e total anual acumulada (PA), no Centro Agroecológico São Miguel, Município de Esperança, PB, de 2003 a 2005. 
foi cultivado o milho solteiro em sistema convencional (sem aléia - SA). Cada parcela dos tratamentos principais foi subdividida em três parcelas de $48 \mathrm{~m}^{2}$ (6x8 m), onde foram implementados os três tratamentos secundários, que correspondem a dois tipos de adubação orgânica: aplicação de $15 \mathrm{t} \mathrm{ha}^{-1}$ de matéria seca (aproximadamente $20 \mathrm{t} \mathrm{ha}^{-1}$ de matéria fresca) de esterco (E); aplicação de $6,40 \mathrm{t} \mathrm{ha}^{-1}$ de matéria seca (aproximadamente $20 \mathrm{t} \mathrm{ha}^{-1}$ matéria fresca) de gliricídia (folhas e galhos finos fragmentados) $(\mathrm{G})$; e tratamento testemunha (T), sem adubação orgânica.

Para evitar interferências das fileiras de árvores nas parcelas do sistema SA, foram escavadas trincheiras nas áreas de bordadura, entre as parcelas com e sem árvores, até a profundidade máxima do solo (aproximadamente 1,20 m). Em seguida, foram colocadas lonas plásticas dentro de cada trincheira, as quais foram preenchidas com o solo retirado, tratando de restaurar o solo o mais próximo possível da situação original.

O esterco utilizado no estudo foi obtido em propriedades rurais da região e continha, na matéria seca, 9,7, 2,3 e $13 \mathrm{~g} \mathrm{~kg}^{-1}$ de N, Pe K, respectivamente. A biomassa de gliricídia utilizada, obtida pelo corte das pontas de ramas com menos de $1 \mathrm{~cm}$ de diâmetro, das plantas presentes na área experimental, continha na matéria seca uma média de 32, 2,4 e $28 \mathrm{~g} \mathrm{~kg}^{-1}$ de N, P e K, respectivamente. Os teores médios de matéria seca, no esterco e gliricídia utilizados, foram 75 e $32 \%$, respectivamente. A biomassa de gliricídia, folhas e galhos finos, foi cortada com um facão, em pedaços com cerca de 10 a $20 \mathrm{~cm}$ de comprimento, para facilitar sua distribuição sobre o solo das parcelas. O esterco e a gliricídia foram incorporados, por meio de enxadas, ao solo das parcelas, até a profundidade de $20 \mathrm{~cm}$, antes do plantio do milho.

O milho (Zea mays L.), da variedade Pontinha, obtido no banco de sementes da AS-PTA, foi plantado na última semana de fevereiro de 2003 e de 2004, e terceira semana de maio de 2005. Foram semeadas duas sementes por cova, com um espaçamento de $1 \times 0,20 \mathrm{~m}$. Duas semanas após a emergência das plântulas, realizou-se o desbaste, tendo-se deixado uma planta por cova $\left(50.000\right.$ plantas ha $^{-1}$ no SA e 41.500 plantas ha- ${ }^{-1}$ no CA). O controle de plantas espontâneas foi realizado com enxada, cerca de 15 a 20 dias após a semeadura do milho.

Na ocasião da colheita do milho, aos 120 dias após a semeadura, foi quantificado o número total de plantas, por fileira e por parcela, e foram realizadas avaliações da produtividade de palha e de grãos. Para isto, em 2003, foram retiradas 20 plantas, ao acaso, de cada parcela (4 plantas por fila). O peso dos grãos e palha das 20 plantas foi determinado e uma subamostra foi pesada e secada em estufa de circulação forçada de ar, a $65^{\circ} \mathrm{C}$, por 72 horas. Com base no número total de plantas, foi estimada a produtividade total de grãos e palha, por parcela.

Em 2004 e 2005, com base em observações prévias de que a produtividade do milho, em parcelas não adubadas, era maior nas posições próximas das fileiras de gliricídia, e que diminuía com o aumento da distância das árvores, foi quantificado e pesado o número total de plantas por fileira de milho de cada parcela (100\% das plantas). As plantas foram divididas em grãos e palha, e uma subamostra de cada um desses materiais foi secada em estufa $\left(65^{\circ} \mathrm{C}\right)$, pesada para determinar a massa de matéria seca e moída, para posterior análise dos teores de nutrientes. A produtividade de grãos foi expressa a $12 \%$ de umidade.

Em 2003 e 2004, as aléias de gliricídia foram podadas à altura de $1 \mathrm{~m}$, duas vezes por ano. O primeiro corte foi realizado no momento de incorporação das fontes orgânicas, antes do plantio do milho, e o segundo foi feito quatro meses após o primeiro corte (final de julho). Em 2005, foi realizada uma única poda, antes do plantio do milho. A quantificação da produção de biomassa da gliricídia foi realizada em cada um dos tratamentos (E, G e T) das áreas consorciadas com gliricídia e milho (CA). Todas as 16 plantas de cada parcela foram podadas, e o peso fresco da biomassa podada foi quantificado. A biomassa produzida pela gliricídia foi agrupada em dois tipos: madeira e folhas+galhos finos (menos de $1 \mathrm{~cm}$ de diâmetro). Subamostras desses materiais foram retiradas, pesadas e secadas em estufa a $65^{\circ} \mathrm{C}$, até atingir peso constante.

Para determinar os teores de N, P e K, no esterco e nas folhas+galhos finos da gliricídia, amostras de $0,25 \mathrm{~g}$ desses materiais foram digeridas em uma mistura de $\mathrm{H}_{2} \mathrm{SO}_{4}+\mathrm{H}_{2} \mathrm{O}_{2}$ (Embrapa, 1999). Nos extratos, foram determinados os teores de $\mathrm{K}$ por fotometria de chama, de $\mathrm{P}$ por colorimetria e de $\mathrm{N}$ pelo método Kjeldahl (Embrapa, 1999).

Também foi quantificada a biomassa da vegetação nativa, nascida espontaneamente nas parcelas após a colheita do milho, nas áreas com ou sem aléias. As amostras foram coletadas com um gabarito de madeira de $1,3 \mathrm{~m}^{2}$, lançado ao acaso sobre 10 pontos, dentro de cada subparcela. O peso total foi determinado, e uma subamostra foi coletada, pesada e secada em estufa de circulação forçada de ar, a $65^{\circ} \mathrm{C}$, por 72 horas, até atingir peso constante. 
Os resultados da produtividade do milho e da vegetação nativa espontânea foram tratados, estatisticamente, pela análise de variância, segundo o delineamento de blocos ao acaso, em parcelas subdivididas, e as médias foram comparadas pelo teste de Tukey, a 5\% de probabilidade. A produtividade de biomassa da gliricídia (folhas+galhos finos e lenha) foi analisada separadamente, como uma ANOVA em blocos ao acaso, com quatro repetições, tendo-se considerado como tratamentos os dois tipos de adubação orgânica e o tratamento testemunha. Para avaliar o efeito das fileiras de gliricídia, sobre a produtividade de grãos e palha de milho, em cada fila de plantio, nos tratamentos E, G e T, foram usados contrastes polinomiais, que permitiram quantificar o gradiente de produtividade com o aumento da distância das fileiras no tratamento CA.

\section{Resultados e Discussão}

Ao longo dos três anos do estudo, a produtividade de matéria seca de grãos e de palha de milho foi, significativamente, maior no sistema sem aléias de gliricídia (SA) do que no sistema com aléias (CA) (Tabela 1). A produtividade de grãos, no sistema SA, foi 268,129 e 116\% maior do que no sistema CA, em 2003, 2004 e 2005, respectivamente. Em média, ao longo dos três anos do estudo, as parcelas sem árvores produziram 1.282, 1.960 e $206 \mathrm{~kg} \mathrm{ha}^{-1}$ a mais de matéria seca de grãos, palha do milho e de vegetação nativa, respectivamente. No entanto, ao se avaliar o efeito das árvores sobre a produtividade do milho, é importante destacar que a população de milho, nas parcelas do tratamento sem árvores, era $17 \%$ superior à população de milho nas parcelas de milho consorciado com gliricídia. Dessa forma, a produtividade de milho nos tratamentos sem árvores pôde ser superior, pelo menos em parte, em razão da maior população de plantas de milho. O cultivo em aléias reduziu a produtividade da cultura associada, em estudos realizados nas Regiões Semi-Áridas da Índia, do Sri Lanka e Savana Central subúmida de Togo (Rao et al., 1991; Schroth et al., 1995; Costa \& Surenthran, 2005).

Rao et al. (1991) observaram na Região Semi-Árida da Índia, uma redução de 58\% da produtividade do milho, no cultivo em aléias com Leucaena leucocephala. Em regiões úmidas, em que a água não é um fator limitante da produtividade, observou-se forte competição, em conseqüência da redução da luz e dos nutrientes (Szott et al., 1991). Segundo Sanchez (1995), de uma maneira geral, o cultivo em aléias só é capaz de aumen- tar a produtividade das culturas agrícolas associadas, em regiões úmidas e de solos férteis, onde a competição por água e nutrientes, entre as árvores e as culturas agrícolas, é reduzida.

No primeiro ano (2003), no sistema de cultivo SA, não foram observados aumentos significativos da produtividade do milho, nos tratamentos com adubação orgânica com esterco (E) e gliricídia (G), quando comparados à testemunha (Tabela 1). Nesse ano, a adubação orgânica $\mathrm{G}$ ou $\mathrm{E}$ aumentou a produtividade de grãos em apenas $6 \%$. O reduzido efeito da adubação orgânica ocorreu, principalmente, porque as parcelas sem aléias estavam em pousio nos anos anteriores ao estudo. Entretanto, o mesmo fato não aconteceu no segundo e terceiro anos de cultivo. Em 2004, os tratamentos E e G aumentaram a produtividade de grãos e palha de milho em cerca de 60 e 50\%, em relação à testemunha, respectivamente. Em 2005, os aumentos com E e G foram acima de 100 e $90 \%$ para grãos e palha, respectivamente. As diferenças (média anual ao longo de todo o período), entre a produtividade de grãos e de palha do milho e da vegetação nativa, para ambos os tipos de adubação orgânica, superaram o controle em cerca de $650,1.000$ e $200 \mathrm{~kg} \mathrm{ha}^{-1}$, respectivamente.

Resultados similares, quanto ao efeito dos adubos orgânicos, foram observados no sistema CA (Tabela 1). Em 2003, nesse sistema, não houve diferenças entre os tratamentos, apesar de a produtividade média de grãos dos tratamentos com adubação orgânica $\left(668 \mathrm{~kg} \mathrm{ha}^{-1}\right)$ ter sido superior à do controle $\left(402 \mathrm{~kg} \mathrm{ha}^{-1}\right)$. Em $2004 \mathrm{e}$ 2005, a produtividade média de grãos e palha do milho, nos tratamentos $\mathrm{G}$ e E, foi 450 e $180 \%$, respectivamente, superiores às do controle. Ao longo de todo o período, a produtividade média de grãos e palha de milho, após a incorporação dos adubos orgânicos, foi cerca de 700 e $1.700 \mathrm{~kg} \mathrm{ha}^{-1}$ superior ao tratamento controle, respectivamente.

A partir do segundo ano, o tratamento $\mathrm{E}$ teve maior efeito residual sobre a produção de matéria seca da vegetação espontânea (Tabela 1). Isso sugere que não seria necessária a aplicação anual do esterco nas áreas, o que permitiria uma rotação na aplicação de esterco nos campos agrícolas, fato esse importante em razão da disponibilidade limitada de esterco para adubação nas propriedades rurais.

Os resultados mostram que, ao longo de três anos, a incorporação de gliricídia ou esterco promoveu aumento da produtividade do milho, intercalado nos sistemas com ou sem aléias, o que está de acordo com outros 
estudos que testaram o uso de adubação orgânica, em sistemas agroflorestais (Agus et al., 1998; Jimenez et al., 1998; Costa \& Surenthran, 2005).

Nas parcelas que não foram adubadas, a produtividade de grãos foi significativamente maior nas linhas próximas às fileiras de gliricídia $(1 \mathrm{~m})$, do que a 2 e $3 \mathrm{~m}$ de distância (Figura 2 A e B). Estudos prévios, conduzidos nesta mesma área experimental, demonstraram que o solo embaixo das árvores e a $1 \mathrm{~m}$ de distância das fileiras de gliricídia possuíam maiores teores de matéria orgânica leve, P e K extraível, e menor umidade que o solo a $3 \mathrm{~m}$ de distância das fileiras (Perez et al., 2006). Isso sugere que o milho produziu mais nas posições próximas às fileiras de gliricídia, porque a baixa disponibilidade de nutrientes do solo, nas parcelas não adubadas, foi mais limitante para o crescimento e desenvolvimento do milho do que a disponibilidade de água.

No caso das parcelas que receberam adubação orgânica, foi observado um efeito quadrático sobre a produtividade de grãos e palha do milho, em relação à distância das fileiras de gliricídia $(\mathrm{p}<0,05)$ (Figura $2 \mathrm{C}, \mathrm{D}, \mathrm{E}$ e F). A produtividade de grãos a $1 \mathrm{~m}$ das árvores foi significativamente menor do que a 2 e $3 \mathrm{~m}$ de distância. No ano de 2004, a 1 m de distância da fileira de gliricídia, a produtividade média de grãos foi 714 e $961 \mathrm{~kg} \mathrm{ha}^{-1}$ para os tratamentos E e G, respectivamente. A 2 e 3 m de distância das fileiras de gliricídia, a produtividade média de grãos, no tratamento G, foi de $1.352 \mathrm{e} 1.522 \mathrm{~kg} \mathrm{ha}^{-1} \mathrm{e}$, no tratamento E foi 1.442 e $1.531 \mathrm{~kg} \mathrm{ha}^{-1}$, respectivamente. Em 2005, a produtividade do milho seguiu o mesmo padrão, e foi superior nas posições mais distantes das árvores.

O ajuste quadrático, nos tratamentos E e G, indicou comportamento oposto ao observado nas parcelas sem adubação, ou seja, a produtividade do milho aumentou, quando a planta distanciou-se das fileiras de gliricídia (Figura 2 C, D, E e F). Esse resultado sugere que, uma vez suprida a deficiência de nutrientes, com a adição dos fertilizantes orgânicos, possivelmente a competição por água e luz passou a limitar a produtividade do milho, nas posições próximas às fileiras de gliricídia.

Tabela 1. Produtividade $\left(\mathrm{kg} \mathrm{ha}^{-1}\right)$ de matéria seca de grãos e palha de milho e de vegetação nativa espontânea, em parcelas cultivadas com e sem aléias de gliricídia, sob dois tipos de adubação orgânica, em três anos consecutivos, em Esperança, PB ${ }^{(1)}$.

\begin{tabular}{|c|c|c|c|c|c|}
\hline Sistemas de cultivo & Adubação orgânica & 2003 & 2004 & 2005 & Média anual \\
\hline & & \multicolumn{4}{|c|}{ Grãos } \\
\hline \multirow[t]{3}{*}{ Sem aléias (SA) } & Esterco & $2.507 \mathrm{a}$ & $2.308 \mathrm{a}$ & $2.205 \mathrm{a}$ & $2.340 \mathrm{a}$ \\
\hline & Gliricídia & $2.506 \mathrm{a}$ & $2.271 \mathrm{a}$ & $1.998 \mathrm{a}$ & $2.258 \mathrm{a}$ \\
\hline & Testemunha & $2.367 \mathrm{a}$ & $1.414 \mathrm{~b}$ & $995 \mathrm{~b}$ & $1.592 \mathrm{~b}$ \\
\hline Média & & $2.460 \mathrm{~A}$ & $1.998 \mathrm{~A}$ & $1.733 \mathrm{~A}$ & $2.063 \mathrm{~A}$ \\
\hline \multirow[t]{3}{*}{ Com aléias (CA) } & Esterco & $655 a$ & $1.169 \mathrm{a}$ & $1.072 \mathrm{a}$ & $965 a$ \\
\hline & Gliricídia & $947 \mathrm{a}$ & $1.230 \mathrm{a}$ & $1.168 \mathrm{a}$ & $1.115 \mathrm{a}$ \\
\hline & Testemunha & $402 a$ & $222 b$ & $165 \mathrm{~b}$ & $263 b$ \\
\hline \multirow[t]{2}{*}{ Média } & & $668 \mathrm{~B}$ & $874 \mathrm{~B}$ & $802 \mathrm{~B}$ & $781 \mathrm{~B}$ \\
\hline & & \multicolumn{4}{|c|}{ Palha } \\
\hline \multirow[t]{3}{*}{ Sem aléias } & Esterco & $4.656 a$ & $5.205 \mathrm{a}$ & $5.778 \mathrm{a}$ & $5.213 \mathrm{a}$ \\
\hline & Gliricídia & $4.339 \mathrm{a}$ & $5.199 \mathrm{a}$ & $4.416 \mathrm{a}$ & $4.651 \mathrm{a}$ \\
\hline & Testemunha & $4.307 \mathrm{a}$ & $3.405 \mathrm{~b}$ & $2.978 \mathrm{~b}$ & $3.563 b$ \\
\hline Média & & $4.434 \mathrm{~A}$ & $4.603 \mathrm{~A}$ & $4.391 \mathrm{~A}$ & $4.476 \mathrm{~A}$ \\
\hline \multirow[t]{3}{*}{ Com aléias } & Esterco & $3.141 \mathrm{a}$ & $2.349 \mathrm{a}$ & $3.504 \mathrm{a}$ & $2.998 \mathrm{a}$ \\
\hline & Gliricídia & $3.521 \mathrm{a}$ & $2.849 \mathrm{a}$ & $3.410 \mathrm{a}$ & $3.260 \mathrm{a}$ \\
\hline & Testemunha & $1.756 \mathrm{~b}$ & $947 b$ & $1.168 \mathrm{~b}$ & $1.290 \mathrm{~b}$ \\
\hline \multirow[t]{2}{*}{ Média } & & $2.806 \mathrm{~B}$ & $2.048 \mathrm{~B}$ & $2.694 \mathrm{~B}$ & $2.516 \mathrm{~B}$ \\
\hline & & \multicolumn{4}{|c|}{ Vegetação nativa espontânea } \\
\hline \multirow[t]{3}{*}{ Sem aléias } & Esterco & $1.118 \mathrm{a}$ & $1.508 \mathrm{a}$ & - & $1.313 \mathrm{a}$ \\
\hline & Gliricídia & $1.183 \mathrm{a}$ & $1.236 \mathrm{~b}$ & - & $1.209 \mathrm{a}$ \\
\hline & Testemunha & $957 \mathrm{~b}$ & $1.055 \mathrm{c}$ & - & $1.006 \mathrm{a}$ \\
\hline Média & & $1.086 \mathrm{~A}$ & $1.266 \mathrm{~A}$ & - & $1.176 \mathrm{~A}$ \\
\hline \multirow[t]{3}{*}{ Com aléias } & Esterco & $683 a$ & $1.510 \mathrm{a}$ & - & $1.096 \mathrm{a}$ \\
\hline & Gliricídia & $630 a$ & $1.287 \mathrm{a}$ & - & $958 \mathrm{a}$ \\
\hline & Testemunha & $513 a$ & $716 \mathrm{~b}$ & - & $614 b$ \\
\hline Média & & 609B & $1.171 \mathrm{~B}$ & - & $890 \mathrm{~B}$ \\
\hline
\end{tabular}

(1)Letras maiúsculas, na coluna, comparam a produtividade de grãos, palha do milho e vegetação nativa espontânea, entre sistemas de cultivo, e letras minúsculas, na coluna, comparam os tipos de adubação orgânica dentro de cada sistema; letras iguais não diferem entre si pelo teste de Tukey, a $5 \%$ de probabilidade. 
O sistema de cultivo, em aléias com gliricídia, diminui a produtividade do milho consorciado. Se a biomassa da gliricídia é retirada para uso como forragem, ao invés
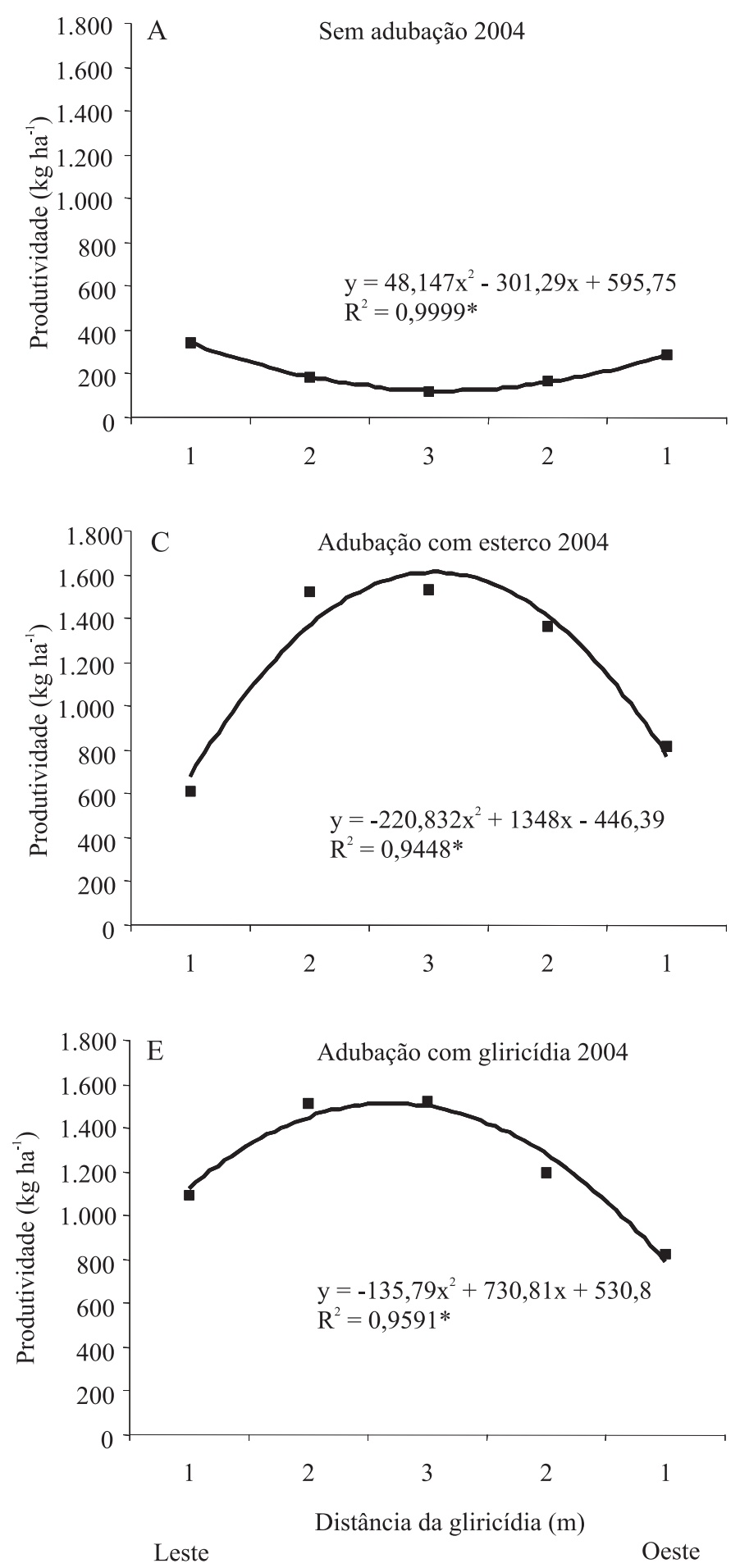

de ser utilizada como adubo-verde, há limitação de nutrientes no solo, para o crescimento e desenvolvimento do milho. Se a biomassa de gliricídia é usada como adu-
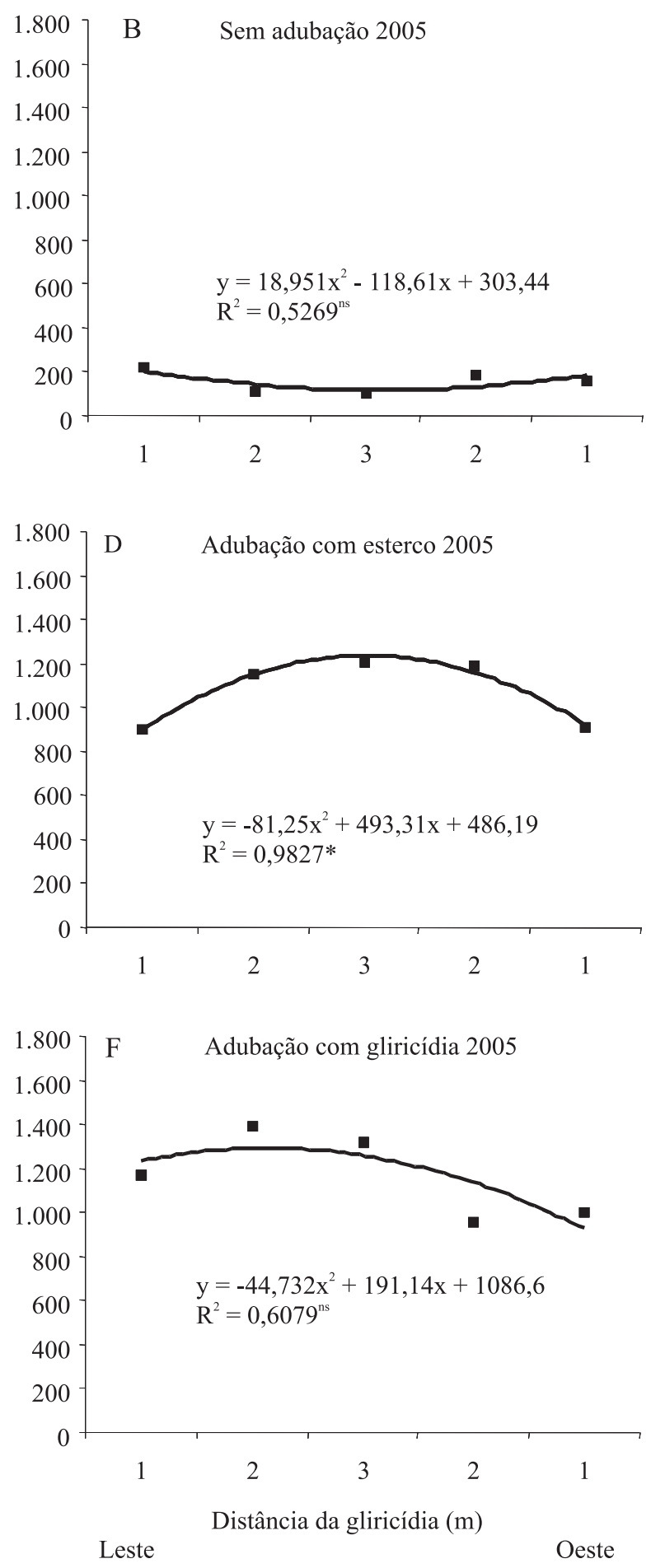

Figura 2. Produtividade de grãos de milho de linhas plantadas em diferentes distâncias das fileiras de gliricídia, cultivada em

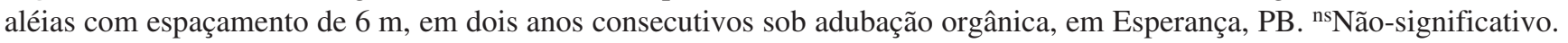
*Significativo a $5 \%$ de probabilidade. 
bo-verde, a competição por água, nas posições próximas às fileiras de gliricídia, limita a produtividade do milho.

A adubação orgânica com esterco e gliricídia não influenciou, significativamente, a produtividade de biomassa da gliricídia (folhas+galhos finos e lenha) (Tabela 2). Entretanto, em 2004, a incorporação de ramas frescas de gliricídia aumentou, significativamente, a produtividade de lenha, em comparação aos tratamentos E e T, o que se refletiu na média anual da produtividade de biomassa pela gliricídia.

A produtividade média de folhas e galhos finos da gliricídia, ao longo dos três anos de estudo, foi 3,3 tha- ${ }^{-1}$, com produtividade média de $1,5 \mathrm{~kg}$ de matéria seca por árvore. Resultados relatados para outros locais diferem dos encontrados neste estudo, principalmente em condições de solo e clima mais favoráveis. Barreto \& Fernandes (2001) avaliaram a produtividade de biomassa da parte aérea da gliricídia cultivada em aléias, com espaçamento de três metros, entre fileiras de gliricídia, em Latossolo Amarelo, no Município de Lagarto, SE, e encontraram valores médios de $5,5 \mathrm{t} \mathrm{ha}^{-1}$ de matéria seca. Em um experimento conduzido em Turrialba, Costa Rica, com alta precipitação $(2.640 \mathrm{~mm})$ e solos com bom nível de fertilidade, Henriksen et al. (2002) obtiveram produtividade média de 14,4 tha-1 de matéria seca.

As concentrações médias de N, P e K na biomassa da gliricídia (folhas+galhos finos), ao longo do estudo, foram 3,32, 0,24 e 2,8\%, respectivamente. A biomassa apresentou alta concentração de $\mathrm{N}$ e $\mathrm{K}$, porém baixo conteúdo de $\mathrm{P}$, comparado aos teores de outras leguminosas. Em 2003, os acúmulos de N, P e K, nas folhas e galhos finos de gliricídia, foram de 126, 9 e $110 \mathrm{~kg} \mathrm{ha}^{-1}$ em média, respectivamente. Em 2004, em razão da maior precipitação e maior produtividade de biomassa pela gliricídia, os acúmulos de nutrientes foram maiores, com valores médios para N, P e K de 219, 16 e $192 \mathrm{~kg} \mathrm{ha}^{-1}$, respectivamente. Comportamento similar foi observado em 2005.

Embora a presença de gliricídia tenha resultado em forte competição por recursos com o milho (grão e palha), o sistema em aléias produziu uma maior quantidade total de biomassa do que o sistema tradicional sem árvores (SA). Somando-se a forragem (folhas e galhos) e lenha produzidas pela gliricídia àquela do milho (grãos e palha) e da vegetação nativa espontânea, o sistema com aléias (CA), nos três anos de cultivo, incrementou a produtividade de biomassa total em 86, 120 e 37\%, respectivamente, em comparação ao sistema sem aléias (Tabela 3). A diferença média, ao longo de todo o período da produtividade de biomassa global, entre os sistemas CA e $\mathrm{SA}$, foi de $6,2 \mathrm{tha}^{-1}$ de MS, o que demonstra que a presença da espécie arbórea, no sistema, aumentou a eficiência de uso dos recursos (água, luz, nutrientes) para a produção de biomassa.

O sistema de cultivo em aléias, com gliricídia, deve ser avaliado pelo saldo dos efeitos positivos e negativos, resultante das relações de complementariedade ou competição entre seus componentes, e sua contribuição à maior sustentabilidade. Portanto, em detrimento de maior produtividade do milho, se estabelece um banco de proteína como estratégia para promover estabilização na produção de biomassa para alimentação animal. Após a colheita do milho, a palhada pode ser recolhida e enfardada para uso como suplemento alimentar volumoso, durante a época seca, e a biomassa proveniente das podas, realizadas durante $\mathrm{o}$ período chuvoso, pode ser utilizada para ensilagem, quando, então, o sistema passaria a desempenhar o papel de banco de proteína.

Tabela 2. Produtividade $\left(\mathrm{kg} \mathrm{ha}^{-1}\right)$ de matéria seca de gliricídia, cultivada em aléias com espaçamento de 6 m entre fileiras, em consórcio com milho, sob dois tipos de adubação orgânica, ao longo de três anos, em Esperança, $\mathrm{PB}^{(1)}$.

\begin{tabular}{|c|c|c|c|c|}
\hline Adubação orgânica $^{(2)}$ & 2003 & 2004 & $2005^{(3)}$ & Média anual \\
\hline \multicolumn{5}{|c|}{ Folhas + galhos finos } \\
\hline Esterco & $3.959 \mathrm{a}$ & $4.078 \mathrm{a}$ & $1.872 \mathrm{a}$ & $3.303 \mathrm{a}$ \\
\hline Gliricídia & $3.999 \mathrm{a}$ & $4.469 \mathrm{a}$ & $1.920 \mathrm{a}$ & $3.463 \mathrm{a}$ \\
\hline Testemunha & $3.865 \mathrm{a}$ & $3.437 \mathrm{a}$ & $1.604 \mathrm{a}$ & $2.967 \mathrm{a}$ \\
\hline \multicolumn{5}{|c|}{ Lenha } \\
\hline Esterco & $6.867 \mathrm{a}$ & $8.791 b$ & $3.172 \mathrm{a}$ & $6.242 \mathrm{ab}$ \\
\hline Gliricídia & $6.937 \mathrm{a}$ & $11.515 \mathrm{a}$ & $3.670 \mathrm{a}$ & $7.351 \mathrm{a}$ \\
\hline
\end{tabular}

${ }^{(1)}$ Letras minúsculas, nas colunas, comparam os tipos de adubação orgânica; letras iguais não diferem entre si pelo teste de Tukey, a 5\% de probabilidade. ${ }^{(2)}$ Esterco: incorporação de esterco $\left(15 \mathrm{t} \mathrm{ha}^{-1}\right)$; gliricídia: incorporação de folhas+galhos finos de gliricídia $(6,4 \mathrm{t}$ ha-1 $)$; testemunha: sem incorporação. ${ }^{(3)}$ Em 2005, foi realizado apenas um corte. 
Tabela 3. Produtividade $\left(\mathrm{kg} \mathrm{ha}^{-1}\right)$ total de biomassa (milho + gliricídia + vegetação nativa espontânea), nos sistemas de cultivo com e sem aléias de gliricídia, sob dois tipos de adubação orgânica, ao longo de três anos, em Esperança, $\mathrm{PB}^{(1)}$.

\begin{tabular}{|c|c|c|c|c|c|}
\hline Sistemas de cultivo & Adubação orgânica ${ }^{(2)}$ & 2003 & 2004 & 2005 & Média anual \\
\hline \multirow[t]{3}{*}{ Com aléias } & Esterco & $15.201 \mathrm{a}$ & $17.895 b$ & $9.621 \mathrm{a}$ & $14.239 \mathrm{~b}$ \\
\hline & Gliricídia & $15.964 \mathrm{a}$ & $21.349 \mathrm{a}$ & $10.169 \mathrm{a}$ & $15.827 \mathrm{a}$ \\
\hline & Testemunha & $13.474 \mathrm{a}$ & $12.765 \mathrm{c}$ & $5.300 \mathrm{~b}$ & $10.513 \mathrm{c}$ \\
\hline Média & & $14.890 \mathrm{~A}$ & $17.337 \mathrm{~A}$ & $8.363 \mathrm{~A}$ & $13.526 \mathrm{~A}$ \\
\hline \multirow{3}{*}{ Sem aléias } & Esterco & $8.288 \mathrm{a}$ & $9.022 \mathrm{a}$ & $7.983 a$ & $8.431 \mathrm{a}$ \\
\hline & Gliricídia & $8.028 \mathrm{a}$ & $8.707 \mathrm{a}$ & $6.414 \mathrm{a}$ & $7.716 b$ \\
\hline & Testemunha & $7.631 \mathrm{~b}$ & $5.874 \mathrm{~b}$ & $3.974 \mathrm{~b}$ & $5.827 \mathrm{c}$ \\
\hline Média & & $7.983 \mathrm{~B}$ & $7.867 \mathrm{~B}$ & $6.123 \mathrm{~B}$ & $7.324 \mathrm{~B}$ \\
\hline
\end{tabular}

${ }^{(1)}$ Letras maiúsculas, nas colunas, comparam a produtividade de biomassa total entre sistemas de cultivo, e letras minúsculas, nas colunas, comparam os tipos de adubação orgânica, dentro de cada sistema; letras iguais não diferem entre si pelo teste de Tukey, a 5\% de probabilidade. (2)Esterco: incorporação de esterco (15 $\left.\mathrm{t} \mathrm{ha}^{-1}\right)$; gliricídia: incorporação de folhas+galhos finos de gliricídia $\left(6,4\right.$ t ha $\left.{ }^{-1}\right)$; testemunha: sem incorporação.

Para evitar a diminuição da fertilidade do solo, recomenda-se que, após o uso da biomassa da gliricídia e da palha do milho como forragem, o esterco produzido pelos animais seja retornado ao solo dos campos de cultivo agrícola, o que também pode ser conseguido através do pastejo direto dos animais na área.

A lenha produzida nesse sistema poderia se tornar uma importante fonte de energia, para atender as necessidades das residências domésticas dos pequenos e médios agricultores, uma vez que a lenha na Região Nordeste representa 33\% da matriz energética (Araújo Filho \& Carvalho, 2001). Além disso, o cultivo em aléias fornece também postes e varas para a confecção de cercas-vivas permanentes. Após a retirada da madeira útil, cuja venda pode custear parte das despesas da propriedade, os garranchos podem ser enleirados em cordões perpendiculares ao declive, para proteção do solo contra a erosão.

\section{Conclusões}

1. O sistema de cultivo em aléias, com gliricídia, reduz a produtividade de grãos e palha de milho, comparado ao milho sem aléias.

2. A incorporação de esterco ou de ramas de gliricídia ao solo aumenta a produtividade de milho, principalmente no sistema de cultivo em aléias.

3. O sistema de cultivo em aléias produz maior quantidade de biomassa total (milho + gliricídia + vegetação nativa espontânea) do que o sistema sem aléias.

\section{Agradecimentos}

Ao CNPq, pela concessão de bolsa; à Capes, à ONG Assessoria e Serviços a Projetos em Agricultura Alternativa (AS-PTA) e ao Inter American Institute for Global Change
Research (IAI), pelo apoio financeiro; a Francisco Brito e às equipes técnicas da AS-PTA e do Laboratório de Fertilidade de Solos, do Dep. de Energia Nuclear, da Universidade Federal de Pernambuco, pelo auxílio nas atividades de campo e laboratório.

\section{Referências}

AGUS, F.; GARRITY, D.P.; CASSEL, D.K.; MERCADO, A. Grain crop response to contour hedgerow systems on sloping Oxisols. Agroforestry Systems, v.42, p.107-120, 1998.

ARAÚJO FILHO, J.A.; CARVALHO, F.C. Sistemas de produção agrosilvopastoril para o Semi-Árido Nordestino. In: CARVALHO, M.M.; ALVIM, J.M.; CARNEIRO, J.C. (Ed.). Sistemas agroflorestais pecuários: opções de sustentabilidade para áreas tropicais e subtropicais. Juiz de Fora: Embrapa Gado Leite; Brasília: FAO, 2001. p.101-110.

BALA, A.; MURPHY, P.; GILLER, K.E. Distribution and diversity of rhizobia nodulating agroforestry legumes in soil from three continents in the tropics. Molecular Ecology, v.12, p.917-930, 2003.

BARRETO, A.C.; FERNANDES, F.M. Cultivo de Gliricidia sepium e Leucaena leucocephala em alamedas visando a melhoria dos solos dos tabuleiros costeiros. Pesquisa Agropecuária Brasileira, v.36, p.1287-1293, 2001.

BURESH, R.J.; TIAN, G. Soil improvement by trees in sub-Saharan Africa. Agroforestry Systems, v.38, p.51-76, 1998.

COSTA, W.A.J.M. de; SURENTHRAN, P. Tree-crop interactions in hedgerow intercropping with different tree species and tea in Sri Lanka: 1. Production and resource competition. Agroforestry Systems, v.63, p.199-209, 2005.

EMBRAPA. Informática Agropecuária (Brasília, DF). Manual de análises químicas de solos, plantas e fertilizantes. 1.ed. Brasília, 1999. 370p.

GATHUMBI, S.M.; CADISCH, G.; BURESH, R.J.; GILLER, K. Subsoil nitrogen capture in mixed legume stands as assessed by deep nitrogen-15 placement. Soil Science Society of America Journal, v.67, p.573-582, 2003. 
GOMÉZ, M.E.; MOLINA, C.H.; MOLINA, E.J.; MURGUEITIO, E. Producción de biomasa en seis ecotipos de matarratón (Gliricidia sepium). Livestock Research for Rural Development, v.2, 1990. Disponível em: <http://www.cipav.org.co/lrrd/lrrd2/3/gomez.htm>. Acesso em: 16 abr. 2007.

HENRIKSEN, I.; MICHELSEN, A.; SCHLÖNVOIGT, A. Tree species selection and soil tillage in alley cropping systems with Phaseolus vulgaris L. in humid premontane climate: biomass, production, nutrient cycling and crop responses. Plant and Soil, v.240, p.145-159, 2002.

JIMENEZ, F.; COLLINET, J.; MAZARIEGO, M. Recuperación de suelos degradados com Gliricidia sepium o gallinaza en la microcuenca río Las Cañas, El Salvador. Revista Agroforestería en las Américas, v.20, p.10-16, 1998.

PALM, C.A.; GILLER, K.E.; MAFONGOYA, P.L.; SWIFT, M.J. Management of organic matter in the tropics: translating theory into practice. Nutrient Cycling in Agroecosystems, v.61, p.63-75, 2001.

PEREZ, A.M.M.; MENEZES, R.S.C.; DIAS, E.M. Efeito da Gliricidia sepium sobre nutrientes do solo, microclima e produtividade do milho em sistema agroflorestal no Agreste paraibano. Revista Brasileira de Ciência do Solo, v.30, p.555-564, 2006.

RAO, M.R.; ONG, C.K.; PATHAK, P.; SHARMA, M.M. Productivity of annual and agroforestry systems on a shallow Alfisol in semiarid India. Agroforestry Systems, v.15, p.51-63, 1991.

ROWE, E.C.; CADISCH, G. Implications of heterogeneity on procedures for estimating plant ${ }^{15} \mathrm{~N}$ recovery in hedgerow intercrop systems. Agroforestry Systems, v.54, p.61-70, 2002.
ROWE, E.C.; VAN NOORDWIJK, M.; SUPRAYOGO, D.; HAIRIAH, K.; GILLER, K.E.; CADISCH, G. Root distributions partially explain ${ }^{15} \mathrm{~N}$ uptake patterns in Gliricidia and Peltophorum hedgerow systems. Plant and Soil, v.235, p.167-179, 2001.

SAMPAIO, E.V.S.B.; SALCEDO, I.H.; SILVA, F.B.R. Fertilidade de solos do Semi-Árido do Nordeste. In: REUNIÃO BRASILEIRA DE FERTILIDADE DOS SOLOS E NUTRIÇÃO DE PLANTAS, 21., 1995, Petrolina. Insumo básico para a agricultura e combate à fome: anais. Petrolina: Embrapa-CPTSA/SBCS, 1995. p.51-71.

SANCHEZ, P.A. Science in agroforestry. Agroforestry Systems, v.30, p.5-55, 1995.

SCHROTH, G.; LEHMANN, J. Contrasting effects of roots and mulch from three agroforestry tree species on yields of alley cropped maize. Agriculture, Ecosystems and Environment, v.54, p.89101, 1995.

SZOTT, L.T.; PALM, C.A.; SANCHEZ, P.A. Agroforestry in acid soils of the humid tropics. Advances in Agronomy, v.45, p.275301, 1991.

TIESSEN, H.; SALCEDO, I.H.; SAMPAIO, E.V.S.B. Nutrient and soil organic matter dynamics under shifting cultivation in Semi-Arid Northeastern Brazil. Agricuture, Ecosystems and Environment, v.38, p.139-151, 1992.

VANLAUWE, B.; GACHENGO, K.; SHEPHERD, E.; BARRIOS, G.; CADISCH, G.; PALM, C.A. Laboratory validation of a resource quality-based conceptual framework for organic matter management. Soil Science Society of America Journal, v.69, p.1135-1145, 2005. 